\title{
INMUNIDAD PARLAMENTARIA VERSUS IGUALDAD CIUDADANA
}

\author{
MARÍA ISABEL MARTÍN DE LLANO \\ Profesora Asociada de Derecho Constitucional \\ Universidad Nacional de Educación a Distancia
}

SUMARIO

I. La inmunidad parlamentaria en el ordenamiento español.

II. La igualdad en la Constitución Española de 1978.

II.1. La igualdad como derecho fundamental.

II.2. La igualdad y la Ley formal.

II.3. El análisis de la desigualdad en sede constitucional.

\section{LA INMUNIDAD PARLAMENTARIA EN EL ORDENAMIENTO ESPAÑOL}

Fundamento básico de la regulación de todo Cuerpo deliberante es un estatuto de los miembros que lo integran; un estatuto que les proporcione las garantías indispensables para llevar a cabo adecuadamente su función. Por ello, el cuerpo parlamentario, emanación directa del poder electoral y representación del pueblo soberano, dispone de una serie de derechos, deberes y prerrogativas, destinados a asegurar la realización de sus importantes funciones en condiciones óptimas.

De esta forma el parlamentario está sujeto a un ordenamiento singular que trata de garantizar la independencia necesaria para el debido ejercicio de sus funciones. A primera vista parece que ese estatuto supone ventajas en favor del parlamentario. Tal criterio no es acertado: de una parte, porque determinados elementos de tal régimen son más limitaciones que privilegios; de otra, porque las prerrogativas de los parlamentarios son más bien "garantías funcionales", que protegen no al parlamentario en cuanto tal, sino a la función parlamentaria que de- 
sempeña, de manera que el parlamentario en su actuación y toma de decisiones no se vea influenciado por factores externos o extraños que pongan en peligro su independencia y, por ende, el funcionamiento mismo de las Cámaras.

Una de las prerrogativas que configuran el Estatuto de los Diputados y Senadores, es la inmunidad parlamentaria que trata de proteger el mantenimiento de la composición de las Cámaras surgida de la voluntad popular, de forma que ésta no se vea afectada por actuaciones policiales o judiciales arbitrarias que impidan a los parlamentarios el ejercicio de sus funciones. Con la inmunidad no se busca una exención para los ilícitos cometidos por Diputados o Senadores, sino garantizar que tras la acusación penal no hay una intención política o partidista de impedir asistir al trabajo de las Cámaras a alguno de sus miembros. Como afirma el Tribunal Constitucional en su reiterada jurisprudencia, la inmunidad parlamentaria no se configura como un derecho personal, sino como un derecho reflejo del que goza cada parlamentario por su condición de miembro de la Cámara ${ }^{1}$.

Esta prerrogativa parlamentaria debe interpretarse de conformidad con los valores y preceptos constitucionales, de forma que no se convierta en privilegio, ni su aplicación suponga la vulneración de derechos fundamentales de otras personas.

Sin embargo, a lo largo de nuestra historia constitucional ha sido una constante el abuso que de la inmunidad parlamentaria han hecho los miembros de las Cámaras Legislativas. La inmunidad aparece como un instrumento utilizado políticamente, de manera que, ante una petición judicial para proceder contra un parlamentario, la decisión de la Cámara depende sobre todo de circunstancias coyunturales y no del trasfondo político que pueda tener la acción penal ejercitada ${ }^{2}$. En demasiadas ocasiones se han denegado suplicatorios sin existir auténticas razones para ello, lo que ha conllevado el archivo definitivo de causas penales en las que aparecía implicado un parlamentario ${ }^{3}$.

Este archivo definitivo se decreta en base al art. 7 de la Ley de 9 de febrero de 1912, sobre jurisdicción y procedimientos especiales en las causas con-

1 SSTC 90/1985, 243/1988, 186/1989, 9/1990, 22/1997.

2 Piénsese en el caso Barrionuevo. Cuando se solicitó el suplicatorio para proceder contra él por detención ilegal (secuestro de Segundo Marey), malversación de caudales, delito relacionado con banda armada y cualquier otro que pudiera aparecer en el curso del procedimiento, era un momento político en que no se tramitaba ninguna norma de importancia dado que se esperaba la inmediata disolución de las Cortes y la convocatoria de nuevas elecciones; sin embargo 122 Diputados votaron en contra de conceder el suplicatorio. En este sentido el entonces líder de Izquierda Unida, D. Julio Anguita, en relación a los que votaron "no", manifestó que "han valorado más el corporativismo, por decirlo de manera suave, que la dignidad y el futuro del Parlamento"; por su parte, el entonces portavoz de Partido Nacionalista Vasco, D. Iñaki Anasagasti, afirmaba que "el respaldo dado al ex ministro es comprensible desde el punto de vista bumano, pero no desde el punto de vista político, ni desde el punto de vista de un partido ético", (Diario El País, 24 de noviembre de 1995).

3 Incluso se han archivado de forma definitiva causas civiles. Pues, hasta la Sentencia del Tribunal Constitucional 9/1990, en la que circunscribe la inmunidad al ámbito penal, se solicitaban y se denegaban suplicatorios para continuar un proceso civil en el que estuviera implicado un parlamentario (esto se produce especialmente en la III Legislatura (1986-1989). 
tra Senadores y Diputados, que establece que "si el Senado o el Congreso denegasen la autorización para procesar, se comunicará el acuerdo al Tribunal requirente que dispondrá el sobreseimiento libre, respecto al Senador o Diputadon.

Pues bien, la amenaza frente a la que protege la inmunidad sólo puede serlo de tipo político, es decir que la vía penal sea utilizada con el fin de alterar la composición o el normal funcionamiento de las Cámaras. Y en este sentido es por lo que la Constitución otorga a las mismas la facultad de analizar esa intencionalidad de la acción penal, permitiendo que las propias Cámaras realicen algo que no pueden llevar a cabo los órganos de naturaleza jurisdiccional como es la valoración sobre el significado político de tales acciones ${ }^{4}$.

El control que corresponde al Tribunal Constitucional no debe consistir en revisar o sustituir esa valoración, pero sí constatar que el juicio de oportunidad o de intencionalidad de la Cámara esté argumentado, esto es, que se haya realizado conforme a la finalidad de la prerrogativa que estudiamos. Así como controlar que la actuación de los Tribunales de Justicia se adecua a los principios constitucionales.

Nosotros nos planteamos si el hecho de que los Tribunales de Justicia ordinarios apliquen el art. 7 de la mencionada de 1912, y decreten el sobreseimiento libre, esto es, el archivo definitivo de la causa penal, cuando la Cámara deniega un suplicatorio, vulnera el artículo 14 de la Constitución respecto a la igualdad de los ciudadanos, una vez que el parlamentario involucrado en dicha causa penal, pierde su condición de Diputado o Senador.

\section{LA IGUALDAD EN LA CONSTITUCIÓN ESPAÑOLA DE 1978}

El artículo 1.1 de la Constitución establece que "España se constituye en un Estado social y democrático de Derecho, que propugna como valores superiores de su ordenamiento jurídico la libertad, la justicia, la igualdad y el pluralismo politico".

Más adelante la Constitución diferencia dos dimensiones de "la igualdad": la igualdad material y la igualdad formal. El artículo 9.2 CE afirma que "corresponde a los poderes públicos promover las condiciones para que la libertad y la igualdad del individuo y de los grupos en que se integra sean reales y efectivas; remover los obstáculos que impidan o dificulten su plenitud ..... Se trata de un mandato dirigido a todos los poderes públicos para que en el ámbito de sus competencias garanticen la igualdad real o material. Mientras, en el artículo 14 CE encontramos la dimensión formal de "la igualdad" al proclamar que "los españoles son iguales ante la ley, sin que pueda prevalecer discriminación alguna por razón de nacimiento, raza, sexo, religión, opinión o cualquier otra condición o circunstancia personal o social.

4 STC 90/1985, Fundamento Jurídico Sexto. 
Con ello, el artículo 1.1 CE establece los pilares básicos del ordenamiento jurídico, entre los que aparece "la igualdad" como valor superior, que encuentra su desarrollo y proyección capital en el artículo 9.2 CE como principio ${ }^{6}$ y en al artículo $14 \mathrm{CE}$ como derecho.

5 El reconocimiento constitucional de la igualdad como valor superior del ordenamiento, constituye el reflejo de la situación en la que se gestó el pacto político y social que dio origen a la Constitución vigente. La opción por la igualdad se corresponde con una voluntad de actuación en el terreno social, común a otras constituciones europeas.

La igualdad es calificada en el artículo1.1 de la Constitución, como "valor superior" del ordenamiento jurídico, esto es, como criterio prioritario y básico para ordenar y enjuiciar la convivencia, y para fijar los objetivos generales a conseguir en el Estado social y democrático de Derecho. En este sentido, la Constitución recoge el ideal igualitarista como cristalización racional e histórica de la idea de dignidad humana en la cultura jurídica moderna.

El problema desde el punto de vista de derecho positivo es el carácter normativo de los valores superiores. Existen autores que consideran que se trata de meras declaraciones programáticoretóricas. Así, JÍMENEZ CAMPOS considera que el artículo 1.1 CE carece por sí sólo de "efectos jurídicos inmediatos" ("La igualdad jurídica como límite frente al legislador", en Revista Española de Derecho Constitucional, n. ${ }^{\circ}$ 9, 1983, p. 79); RUBIO LLORENTE, en su voto particular en la Sentencia del Tribunal Constitucional 53/1985, afirma que cuando el Tribunal Constitucional argumenta sus sentencias en torno a los valores lo hace de forma "puramente retórica, que no extrae de la consagración constitucional del valor ninguna conclusión que no esté apoyada en otros preceptos de la Constitución" de forma que ninguna de sus decisiones "se ha basado nunca en la vulneración de uno de esos valores para declarar la inconstitucionalidad de una ley, ni parece posible que jamás lo hagan.

Otros autores, sin embargo, sí atribuyen carácter normativo a los valores proclamados en la Constitución. PECES BARBA considera que los valores tienen auténtico carácter normativo, son verdaderas normas jurídicas que vinculan a todos y especialmente a los operadores jurídicos. Se trata de los ideales éticos de una comunidad positivizados por el poder, que constituyen una moral legalizada (Los valores superiores, Madrid, Tecnos, 1984; y Etica, poder y Derecho: reflexiones ante el fin de siglo, Madrid, Centro de Estudios Constitucionales, Serie Cuadernos y Debates, n. ${ }^{\circ} 54,1995$, pp. 58 y ss.).

PRIETO SANCHÍS entiende que los valores superiores poseen auténtica fuerza normativa, pero su función esencial no es tanto resolver conflictos jurídicos concretos, cuanto condicionar y orientar el proceso interpretativo, hasta el punto de que adquieren pleno sentido como pautas de interpretación (Ideología e interpretación jurídica, Madrid, Tecnos, 1987, p. 123).

El Tribunal Constitucional considera que la Constitución incorpora un sistema de valores, cuya observancia requiere una interpretación finalista (STC 18/1981, de 8 de junio); y afirma que la igualdad se configura como un valor superior que se proyecta con una eficacia trascendente, de modo que toda situación de desigualdad persistente deviene incompatible con el orden de valores que la Constitución, como norma suprema, proclama (STC 8/1983, de 18 de febrero).

$\mathrm{Y}$ aunque el Tribunal Constitucional en sus sentencias normalmente utiliza el valor igualdad conjuntamente con la igualdad como principio (STC 86/1985), o como derecho fundamental (SSTC 86/1985; 128/1987), en aquellos casos en los que no ha encontrado un precepto en el que basar el fallo, ha recurrido al valor igualdad positivizado en el artículo 1.1 CE. Así en la STC 214/1991 (Fj. 3. ${ }^{\circ}$ ), fundamenta la legitimación de una de las partes en que de lo contrario "el Estado español de Derecho permitiría el surgimiento de campañas discriminatorias, racistas o de carácter xenófobo, contrarias a la igualdad, que es uno de los valores superiores del ordenamiento jurídico que nuestra Constitución proclama en el art. 1.1".

6 La Constitución también formula la igualdad como "principio", y lo hace en dos aspectos: desde el punto de vista de igualdad real o sustancial (art. 9.2 CE); y desde el punto de vista de igualdad formal o ante la ley (art. $14 \mathrm{CE}$ ).

El artículo 9.2 CE establece que corresponde a los poderes públicos "promover las condiciones para que la libertad y la igualdad del individuo y de los grupos en que se integra sean reales y 


\section{II.1. LA IGUALDAD COMO DERECHO FUNDAMENTAL}

Además de como valor y principio, la igualdad aparece recogida en nuestra Constitución como derecho fundamental en su doble manifestación de derecho a un trato igualy derecho a no ser discriminado.

Sin embargo, el hecho de que el artículo 14 de la Constitución esté fuera de la Sección Primera del Capitulo segundo del Titulo I de la Constitución ("De los derechos fundamentales y libertades públicas"), ha llevado a algunos autores a negar la categoría de derecho fundamental a la igualdad ${ }^{7}$. A ello hay

efectivas"; mientras, el art. $14 \mathrm{CE}$ afirma que "los españoles son iguales ante la ley sin que pueda prevalecer discriminación alguna por razón de raza, sexo, religión, opinión o cualquier otra condición o circunstancia personal o social».

La igualdad ante la ley es la que se realiza predominantemente en el plano del derecho, y de los derechos y deberes jurídicos; mientras que la igualdad sustancial, de carácter ideal y más difícil de realizar, propone modelos de mayor igualdad en el plano social, económico y cultural.

La igualdad formal, generada en el contexto del pensamiento liberal como igualdad ante la ley y vinculada a la seguridad jurídica, es ciertamente una exigencia mínima, indiscutida e irrenunciable, pero insuficiente. No basta con que el Estado dicte normas no discriminatorias y prohiba la discriminación negativa, sino que ha de adoptar medidas para conseguir condiciones sociales cada vez más igualitarias (MARTÍNEZ TAPIA: Igualdad y razonabilidad en la justicia constitucional española, Almería, Universidad de Almería, 2000, p. 58). Por ello, tanto la doctrina como el Tribunal Constitucional consideran que el principio de igualdad material ha de ser entendido como una reinterpretación de la igualdad formal en el Estado social de Derecho.

El Tribunal Constitucional considera que el artículo 9.2 CE es el "reflejo inmediato del carácter social del Estado de Derecho " ( STC 55/1994, de 24 de febrero ), y que la igualdad allí proclamada "exige una política legislativa que no puede reducirse a la pura igualdad ante la ley" (STC 27/1981, de 20 de junio). En esta última Sentencia el Tribunal rechaza una interpretación formalista de la igualdad, y considera necesario dar una interpretación material del principio de igualdad establecido en el artículo 9.2 CE. Así, afirma que «la finalidad de promover la igualdad del individuo y de los grupos en que se integra, en ocasiones, exige una política legislativa que no puede reducirse a la pura igualdad ante la ley". En la STC 34/1981 (Fj. $\left.3^{\circ}{ }^{\circ}\right)$ dice que "El principio de igualdad jurídica consagrado en el art. 14 (...) no prohibe que el legislador contemple la necesidad o conveniencia de diferenciar situaciones distintas y darle un tratamiento diverso, que puede, incluso venir exigido en un Estado social y democrático de Derecho por la efectividad de los valores que la Constitución consagra con el carácter de superiores del Ordenamiento, como son la justicia y la igualdad (art. 1), a cuyo efecto atribuye, además, a los poderes públicos el que promuevan las condiciones para que la igualdad sea real y efectiva". Y en la STC 3/1983 establece que "el artículo 14 de la CE, que consagra la igualdad de todos los españoles ante la ley, no establece un principio de igualdad absoluta que pueda omitir tomar en consideración la existencia de razones objetivas que razonablemente justifiquen la desigualdad de tratamiento legal (...) con el artículo 9.2 de la CE se supera el más limitado ámbito de actuación de una igualdad meramente formal, propugnando un significado del principio de igualdad acorde con la definición del artículo 1 que constituye a España como un Estado democrático y social de Derecho .....

7 Así, BASILE afirma que la igualdad no es un derecho sino "un modo objetivo de ser la ley" ( LLos valores superiores, los principios fundamentales, y los derechos y libertades públicas", en $L a$ Constitución Española de 1978: estudio sistemático (dirigido por A. Predieri y E. G. ${ }^{a}$ de Enterría), Madrid, Civitas, 1980, p. 277); GALVEZ sostiene que no es uno más entre los derechos y libertades que se proclaman sino que es "uno de los presupuestos necesarios para la efectividad de aquellos" ("El Artículo 14 CE", en Comentarios a la Constitución Española (Garrido Falla), Madrid, Civitas, 2001, p. 183); o DE VEGA que configura la igualdad como "una condición general para el mante- 
que sumar la interpretación realizada por el Tribunal Europeo de Derechos Humanos de Estrasburgo del artículo 14 del Convenio Europeo para la protección de los Derechos Humanos de 1950, que rechaza la igualdad como derecho fundamental, considerándola como "una garantía circunscrita a la defensa de los derechos reconocidos en la Convención" y como "parte integrante de cada uno de los artículos que consagra derechos y libertades" ${ }^{8}$. Algo que influyó notablemente en la inicial jurisprudencia de nuestro Tribunal Constitucional que negó expresamente el carácter de derecho fundamental a la igualdad (SSTC 10/1981, Fj. 6. ${ }^{\circ} ; 22 / 1981, F j . ~ 3 .{ }^{\circ} ; 27 / 1981, ~ F j . ~ 3 .{ }^{\circ} ;$ 76/1983, Fj. $\left.2^{\circ}\right)$, afirmando que el artículo $14 \mathrm{CE}$ únicamente posee "carácter informador" (STC 4/1981, Fj. $1 .^{\circ}$ y $10 .^{\circ}$ ).

Frente a estas posiciones, la mayoría de los autores entienden que la igualdad es un derecho fundamental. Si bien, dentro de estas posiciones existen quienes consideran la igualdad como derecho relacional, sin sustantividad

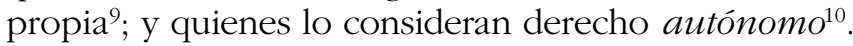

nimiento y aplicación de los derechos primarios" (Proceso penal y derechos fundamentales desde la perspectiva jurisprudencial, Madrid, Colex, 1994, p. 20).

8 En este sentido STEDH de 23 de julio de 1968, Fd. I-B, epígrafe 8 y siguientes; STEDH de 27 de octubre de 1976, fd. II, epígrafe 44; STEDH de 13 de junio de 1979, Fd. II, epígrafe 32.

9 GARCíA MORILLO, considera la igualdad como derecho conexo. Dado su carácter relativo no es un título que pueda contener per se una pretensión contra alguien, si no que siempre ha de estar conectado a otros derechos fundamentales ("La cláusula general de igualdad", en Derecho Constitucional, v. I (López Guerra y otros), Valencia, Tirant lo Blanch, 1995, p. 160). No se viola la igualdad en abstracto, si no que su propia naturaleza exige que su transgresión se proyecte sobre algún campo material concreto. SUAY-RINCÓN entiende que la igualdad es un derecho sin vida propia porque "aparece siempre en relación con otro" (El principio de igualdad en la justicia constitucional, IEAL, Madrid, 1985, p. 152).

10 Distintos autores entienden que el que se conciba como un derecho prototípicamente relacional y genérico, no es razón suficiente para negarle el carácter de derecho autónomo. Entendido como derecho que no sólo prohibe cualquier trato desigual, sino especialmente, cualquier trato que conlleve una desvaloración o negación de la condición de ser humano. Derecho fundamental que protege la igualdad de trato y rechaza toda desigualdad arbitraria.

PÉREZ LUÑO lo define como eel derecho fundamental que tiende a asegurar un determinado "status" subjetivo, es decir, una determinada esfera de los ciudadanos, concretada en la garantía de la paridad de trato y la consiguiente prohibición de una serie - no cerrada ni exhaustiva- de discriminaciones" (Sobre la igualdad en la Constitución española, en Anuario de Filosofía del Derecho, n. ${ }^{\circ}$ 4, Madrid, 1987 , p.151).

CANO MATA, concibe este derecho como aun derecho subjetivo de los ciudadanos a obtener un trato análogo" (El principio de igualdad en la doctrina del Tribunal Constitucional, Madrid, Edersa, 1983, p. 8). RODRÍGUEZ-PINEIRO, entiende la igualdad como "un derecho a ser tratado de forma igual (...) objeto de protección en los mismos términos que los restantes derechos fundamentales, no por asimilación al régimen jurídico de éstos, sino por plena identificación en cuanto a su naturaleza" (Igualdad y discriminación, Madrid, Tecnos, p. 255).

PUY defiende la igualdad como "derecho fundamental que tiene todo ser humano, frente a todos los poderes públicos, estatales o sociales, y para toda la gestión pública, pero en especial la normativa, $1 .{ }^{\circ}$ a ser calificado indiscriminadamente por la ley; $2{ }^{\circ}$ a ser tratado imparcialmente por los administradores, $3 .^{\circ}$ a recibir de todos los operadores sociales, dentro del grupo de referencia, un número de oportunidades de ejercicio de todos los derechos y libertades, equivalente al que reciban los más afortunados consocios" ("El derecho a la igualdad en la Constitución española", en $E l$ 
El mismo Tribunal Constitucional, a pesar de su jurisprudencia inicial que algún autor ha llegado a calificar de "obsoleta"", en sentencias posteriores no duda en considerar la igualdad como un derecho fundamental autónomo. Así en la Sentencia 49/1982 ${ }^{12}$ define el derecho a la igualdad como "el derecho subjetivo a obtener un trato igual"; la STC $142 / 1985^{13}$ se refiere al "derecho fundamental... de igualdad consagrado en el artículo 14 CEn; la STC 166/1985 ${ }^{14}$ considera que el derecho fundamental garantizado en el artículo $14 \mathrm{CE}$ incluye, no sólo la igualdad ante la ley, sino también la igualdad en la aplicación de la ley; en la STC 8/1986 ${ }^{15}$ afirma el Alto Tribunal que "el art. 14 CE establece el principio de igualdad jurídica o igualdad de los españoles ante la ley, que constituye por imperativo constitucional, un derecho fundamental de la persona a no sufrir discriminación jurídica alguna, esto es, a no ser tratada jurídicamente de manera diferente a quienes se encuentren en su misma situación, sin que exista una justificación objetiva y razonable de esa desigualdad de trato".

Todo ello nos lleva a afirmar que la Constitución no se limita a reconocer la igualdad como derecho fundamental (art. 14 CE). Por el contrario, la igualdad aparece en el texto constitucional con una reiteración similar a la que se produce con otros principios como la libertad o la democracia, erigiéndose en valor superior de nuestro ordenamiento jurídico, lo que supone un plus añadido de protección constitucional.

El hecho de que el artículo 14 CE esté fuera de la Sección Primera del Capítulo Segundo del Título Primero, no es motivo suficiente para no reconocer la igualdad como derecho fundamental. Todo lo contrario, podemos afirmar que por su enclave en el texto constitucional, el derecho a la igualdad es singularizado respecto de los demás derechos fundamentales, de modo que la igualdad encabeza los derechos y libertades comprendidos en el Capítulo Segundo.

Es indudable que la igualdad no se agota como derecho especialmente protegido, sino que además tamiza el texto constitucional como valor superior del Ordenamiento Jurídico lo que implica una relevancia jurídica singular y diferenciada de la que todo derecho conlleva en cuanto expresión de valores y principios constitucionales.

\section{II.2. LA IGUALDAD Y LA LEY FORMAL}

El Derecho opera mediante la definición de supuestos de hecho a los que se atribuyen consecuencias jurídicas. Ahora bien, no existe ningún sistema ju-

principio de igualdad en la Constitución española (XI jornadas de estudio), v. I, Madrid, Ministerio de Justicia, 1991, p. 154).

11 PUY, F.: "El derecho a la igualdad en la Constitución española", en El principio de igualdad en la Constitución española (XI jornadas de estudio), v. I, Madrid, Ministerio de Justicia, 1991, p. 143.

12 STC 49/1982, de 14 de julio, Fj. 2. ${ }^{\circ}$ En el mismo sentido, STC 2/1984 de 24 de enero, Fj. 4. ${ }^{\circ}$

13 STC 142/1985, de 23 de octubre, Fj. $1 .^{\circ}$

14 STC 166/1985, de 9 de diciembre, Fj. 5. ${ }^{\circ}$

15 STC 8/1986, de 21 de enero, Fj. 4 . $^{\circ}$ 
rídico que establezca que deba tratarse absolutamente a todos los ciudadanos por igual. Como dice Alexi ${ }^{16}$ si el legislador tuviera que colocar a todos en las mismas posiciones jurídicas y situar a todos en las mismas posiciones fácticas, se vería obligado a dictar normas no funcionales, disparatadas e injustas, que harían imposible el funcionamiento de la sociedad.

A través del Derecho se realiza una tarea clasificadora y de justificación, que consiste en establecer los criterios legítimos conforme a los cuales se tratará una situación en términos de equiparación o de diferenciación. El Derecho considera como iguales a personas que son entre sí extremadamente diferentes en todo, salvo en aquel rasgo que la norma toma en consideración. Por ello, la igualdad es tanto "equiparación" como "diferenciación". Ahora bien, así como la igualdad no tiene necesidad de ser justificada, un tratamiento desigual, si no quiere ser arbitrario, requiere una razón que lo justifique ${ }^{17}$.

La igualdad obliga al legislador a equiparar a los ciudadanos, de forma que no pueda dar valor jurídico a las circunstancias productoras de diferencias no consideradas relevantes (igualdad como equiparación o diferenciación negativa), y a excluir como criterios legales diferenciadores los expresamente prohibidos en el artículo $14 \mathrm{CE}$ (igualdad como no discriminación); pero también le permite establecer diferencias y desigualdades legítimas (igualdad como diferenciación positiva). Lo que lesiona la igualdad no es la diferenciación normativa, sino el establecimiento de distinciones discriminatorias arbitrarias, es decir, no fundadas en razones jurídicamente atendibles ${ }^{18}$.

La igualdad supone un límite al legislador, que no debe dictar normas discriminatorias, y en caso de que lo haga se verá abocado a la declaración de inconstitucionalidad de las mismas por parte del Tribunal Constitucional. Desde un principio se pronuncia en este sentido nuestro Tribunal Constitucional, que al plantearse si el principio de igualdad vincula a todos los poderes públicos, incluido el legislativo, afirma que uninguna duda puede caber de que el legislador está obligado a observar el principio de igualdad, dado que su inobservancia puede dar lugar a la declaración de inconstitucionalidad de la ley" (STC 34/1981).

Ahora bien, si en determinados casos la Constitución permite un trato normativo distinto respecto a los ciudadanos, la dificultad está en determinar cuándo la desigualdad es legítima o permitida por el Derecho, y cuándo es ilegítima o prohibida por el Ordenamiento. Es decir cuándo podemos afirmar que una actuación, provenga del órgano que provenga, es arbitraria o no.

El Diccionario de la Real Academia de la Lengua Española define la $a r b i$ trariedad como eel acto o proceder contrario a la justicia, la razón o las leyes, dictado solo por la voluntad o el capricho" ${ }^{19}$. Un órgano del Estado actuará ar-

16 ALEXI, R.: Teoría de los derechos fundamentales, Madrid, Centro de Estudios Constitucionales, 1993 , p. 384.

17 MARTÍNEZ TAPIA, RAMÓN: Igualdad y razonabilidad..., op. cit., p. 93.

18 Ibidem, p. 97.

19 Diccionario de la Lengua Española, Real Academia Española, vigésima primera edición, Madrid, 2000. 
bitrariamente cuando su actuación no esté sometida a las normas previamente establecidas. En este sentido como afirma Ihering ${ }^{20}$ cuando el súbdito "contraviene la ley obra ilegalmente, no arbitrariamente. La arbitrariedad es la injusticia del superior".

Siguiendo a Martínez Tapia ${ }^{21}$, el concepto de arbitrariedad se vincula negativamente, a la motivación jurídica. El Derecho exige siempre justificación, demanda razones y la arbitrariedad es la ausencia de ellas. Aplicando este criterio a la igualdad, se producirá arbitrariedad cuando no se ofrece una fundamentación objetiva del trato desigual, o ésta no es suficiente.

El Tribunal Constitucional entiende que existe arbitrariedad en la ley cuando engendra desigualdad sin fundamento objetivo o razonable (STC 108/1986, Fj. 3. ${ }^{\circ}$ ); o cuando existe desproporción entre el fin perseguido y los medios empleados, que implique un sacrificio excesivo e innecesario de derechos fundamentales (STC 66/1985). Es decir, en el juicio de igualdad se hace imprescindible la averiguación de los fines de la norma y de pertinencia de la misma al logro de ese fin.

Además, el Tribunal Constitucional, en reiterada jurisprudencia, considera que el legislador sólo puede «establecer para los ciudadanos un trato diferenciado: a) cuando tenga que resolver situaciones diferenciadas fácticamente que requieran en su solución por su mismo contenido una decisión distinta, pero a tal fin, b) resulta indispensable que exista una justificación objetiva y razonable, de acuerdo con juicios de valor generalmente aceptados, cuya exigencia debe aplicarse en relación con la finalidad y efectos de la medida considera$d a, c)$ debiendo estar presente una razonable relación de proporcionalidad entre los medios empleados y la finalidad perseguida, y dejando al legislador, con carácter general, la apreciación de situaciones distintas que sea procedente diferenciar y tratar desigualmente, siempre que su acuerdo no vaya contra los derechos y libertades protegidos en los artículos 53.1 y 9.3 de la Constitución, ni sea irrazonada" ${ }^{22}$.

En la STC 76/199023 afirma que "para que la diferenciación resulte constitucionalmente legítima no basta con que lo sea el fin que con ella se persigue, sino que es indispensable, además, que las consecuencias jurídicas que resultan de tal distinción sean adecuadas y proporcionadas a dicho fin, de manera que la relación entre la medida adoptada, el resultado que se produce y el fin pretendido por el legislador superen un juicio de proporcionalidad en sede constitucional, evitando resultados especialmente gravosos y desmedidos. Y en la STC 222/1993 ${ }^{24}$ fija una triple exigencia al legislador, de forma que las "diferenciaciones normativas habrán de mostrar, en primer lugar, un fin discernible y legítimo, tendrán que articularse, además, en términos no inconsis-

20 IHERING, R.V.: El fin del Derecho, V. I, Puebla, Cajica, 1961, p. 263.

21 MARTÍNEZ TAPIA, RAMÓN: Igualdad y razonabilidad..., op. cit., p. 105.

22 STC 75/1983, Fj. 2. ${ }^{\circ}$

23 STC 76/1990, Fj. 2. ${ }^{\circ}$

24 STC 222/1993, Fj. 6. ${ }^{\circ}$ 
tentes con tal finalidad, y deberán, por último, no incurrir en desproporciones manifiestas a la hora de atribuir a los diferentes grupos y categorías derechos, obligaciones o cualesquiera otras situaciones jurídicas subjetivas ${ }^{25}$.

Por ello, el control al que debe someterse una norma a la luz de la igualdad es el relativo a su finalidad. Para que la diferencia de trato esté constitucionalmente justificada ha de tener una finalidad, lo que obliga a averiguar cuál es esa finalidad perseguida por la norma que determina la desigualdad. Ese fin perseguido por la norma servirá de módulo al Tribunal Constitucional para establecer la conformidad o no de aquélla con la Constitución.

Pero no hay que olvidar que con la entrada en vigor de la Constitución de 1978, varía radicalmente la posición de los jueces frente a la ley. La aplicación de la Constitución por los jueces conlleva una mayor disponibilidad de las normas constitucionales respecto de los Tribunales ordinarios, a quienes les corresponde ejercer la "jurisdicción constitucional limitada", esto es, se reconoce la capacidad del Juez para realizar una interpretación de las normas infraconstitucionales que defina su sentido más acorde con los preceptos constitucionales. El Juez tiene la obligación de realizar una interpretación de todo el Ordenamiento Jurídico conforme con la Constitución.

Como afirma Rubio Llorente ${ }^{26}$ el Tribunal Constitucional es el intérprete supremo de la Constitución, pero no el único. Los Jueces y Tribunales ordinarios están obligados a interpretar la Constitución y a declarar derogadas las normas anteriores que se le opongan, o inconstitucionales las posteriores con rango infralegal que la infrinjan, así como a solicitar un pronunciamiento del Tribunal Constitucional respecto a aquellas leyes postconstitucionales cuya constitucionalidad les parezca cuestionable.

\section{II.3. El análisis de la Desigualdad en SEDE CONSTituCiOnal}

Todo juicio de constitucionalidad es un juicio de razonabilidad abierto a consideraciones valorativas, teleológicas y prudenciales, en el que el Tribunal Constitucional debe ser especialmente convincente ${ }^{27}$.

El juicio de razonabilidad se encuentra a medio camino entre la deducción más o menos estricta de la justicia ordinaria y el juicio de optimización política, y coincide con el juicio de constitucionalidad tanto por su contenido (sólo lo razonable es constitucional), como en su límite (dentro del marco de la razonabilidad todas las soluciones son constitucionalmente válidas, porque todas son objetivamente no arbitrarias). Se trata, por tanto, de un juicio complejo donde se mezclan decisiones de valor matizadas por la razonabilidad, ciertas apreciaciones de carácter político, concretadas únicamente en criterios de admisibilidad y

25 En el mismo sentido, SSTC 59/1982, 7/1984, 106/1994, 155/1998, entre otras.

26 En su voto particular formulado en la STC 4/1981, de 2 de febrero.

27 En este sentido PRIETO, L.: "Notas sobre la interpretación constitucional", en Revista del Centro de Estudios Constitucionales, n. ${ }^{\circ}$ 9, 1991, pp. 117 y ss. 
no de excelencias, y, sobre todo, el carácter jurídico de aquella decisión bajo la cobertura de un proceso materialmente y no ya sólo formalmente justo ${ }^{28}$.

La dificultad está en cómo discernir la razonabilidad de una decisión normativa que establece un trato diferente; qué causas han de darse para que un tratamiento desigual sea razonable, es decir, sea conforme a Derecho.

Sirviéndonos de lo que Martínez Tapia ${ }^{29}$, denomina test de constitucionalidad de la desigualdad ${ }^{30}$, vamos a analizar en qué medida la "Ley sobre jurisdicción y procedimientos especiales en las causas contra Senadores y Diputados", de 9 de febrero de 1912, es o no razonable en la actualidad, esto es, es contraria o no a la Constitución de 1978.

La estructura del test de constitucionalidad de la desigualdad consta de cuatro fases: $a$ ) constatación de la consagración normativa de la desigualdad; $b$ ) existencia de un término de comparación c) averiguación de cuál es la finalidad perseguida por la norma consagradora de la desigualdad, y su compatibilidad con los principios y valores constitucionales; y, d) análisis de la existencia de una relación razonable de proporcionalidad entre los medios empleados y los fines perseguidos.

\section{a) Comprobación de la desigualdad}

En este primer paso se trata de comprobar la efectiva existencia de una desigualdad normativa. Si las situaciones de hecho son iguales, el trato diferente será, en principio, discriminatorio pues la igualdad se viola cuando se trata desigualmente a los iguales.

En nuestro caso cuando el artículo 71.2 de la Constitución establece que "Durante el periodo de su mandato los Diputados y Senadores gozarán asimismo de inmunidad y sólo podrán ser detenidos en caso de flagrante delito. No podrán ser inculpados ni procesados sin la previa autorización de la Cámara respectiva", está colocando al parlamentario en una posición distinta a la que probablemente se encuentre la otra parte del proceso judicial en que nos encontremos. Esto es, no se puede considerar que estemos ante situaciones parejas o comparables entre sí, y en ese sentido no se estaría vulnerando el derecho fundamental a la igualdad.

Sin embargo, esa desigualdad sí existe en relación a las normas accesorias (que se convierten en principales) del proceso en el que se ve incurso un parlamentario, esto es, el artículo 754 de la Ley de Enjuiciamiento Criminal en relación con la Ley de 9 de febrero de 1912. El primero establece que si el Sena-

28 CARRASCO, A.: "El juicio de razonabilidad en la justicia constitucional", en Revista Española de Derecho Constitucional, n. ${ }^{\circ} 11,1984$, p. 54.

29 MARTÍNEZ TAPIA, RAMÓN: Igualdad y razonabilidad..., op. cit., p. 116

30 MARTÍNEZ TAPIA configura este test de constitucionalidad, partiendo de los criterios de control de la discriminación legislativa elaborados por el Tribunal Constitucional a lo largo de sus sentencias. 
do o el Congreso negasen el suplicatorio, la causa se sobreseerá respecto al parlamentario afectado, continuando contra los demás procesados; mientras, el artículo 7 de la Ley de 1912 establece que "si el Senado o el Congreso denegasen la autorización para procesar, se comunicará el acuerdo al Tribunal requirente que dispondrá el sobreseimiento libre, respecto al Senador o Diputado".

La desigualdad normativa existe respecto al momento en que se decreta el sobreseimiento libre, puesto que al tener efecto de cosa juzgada, no se podrá reabrir el proceso en relación al parlamentario una vez que éste haya perdido la condición de tal.

\section{b) Exigencia de un término de comparación}

Para que podamos analizar si existe desigualdad o no, es necesario que exista un término de comparación. En nuestro caso, éste aparece en el momento en que el parlamentario, que se vió incurso en un proceso penal sobreseído por denegarse el suplicatorio, pierde la condición de tal.

$\mathrm{Si}$ el parlamentario deja de serlo, estaremos ante un ciudadano de a pie más, que podrá verse incurso sin limitación alguna en cualquier proceso penal. El hecho de que sea detenido, procesado o incluso condenado, no afectará en absoluto a la composición ni al buen funcionamiento de las Cámaras Legislativas, puesto que ya no forma parte de ellas.

Mientras que en la parte contraria nos encontraremos ante una persona que, afectada por la presunta actuación ilícita de un ex-parlamentario, no puede ver satisfechas sus pretensiones ante los Tribunales de justicia.

\section{c) El fin perseguido por la norma y su afectación a los principios $y$ valores constitucionales}

Comprobada la existencia de un trato objetivamente desigual, tendremos que determinar si dentro del ordenamiento existen razones justificativas de la desigualdad. Se trata de controlar el razonamiento jurídico realizado por el legislador (o los jueces), así como de los criterios diferenciadores utilizados para establecer la desigualdad.

Ante una diferenciación normativa lo que hace el juzgador constitucional no es sobreponerse al legislador, determinando por sí mismo igualdades o diferencias entre los supuestos de hecho, sino partir del valor asumido por quien hace la ley, y velar para que la articulación de dicho objetivo-valor en una opción normativa determinada no se haga en términos arbitrarios ${ }^{31}$.

Como hemos dicho, el Derecho se justifica en razón a sus fines, y por eso, el primer control al que debe someterse una norma a la luz de la igualdad

31 JIMÉNEZ CAMPOS, J.: “La igualdad jurídica como límite frente al legislador” en Revista Española de Derecho Constitucional, n. ${ }^{\circ}$ 9, 1983, pp. 90-93. 
es el relativo a su finalidad, teniendo en cuenta que dicho fin ha de ser constitucionalmente lícito. La finalidad cumple, así, en la jurisdicción constitucional una importante función: la de apreciar lo razonable de la norma y de la desigualdad. En consecuencia, el control de la constitucionalidad de un precepto se realiza sobre su finalidad, que va a servir de módulo al Tribunal Constitucional para establecer la conformidad o no de aquél con la Constitución ${ }^{32}$.

Como hemos venido analizando hasta el momento la razón de ser de la inmunidad parlamentaria reside en la protección del conjunto de funciones parlamentarias llevadas a cabo por Diputados y Senadores. Se trata de evitar que la vía penal se utilice con el fin de alterar la composición o el normal funcionamiento de las Cámaras; por ello la Constitución otorga a las mismas la facultad de analizar la intencionalidad de la acción penal, permitiendo que valoren el significado político de tales acciones.

El fin que persigue la inmunidad parlamentaria puede responder a cierta razonabilidad y, así, considerar el fin perseguido por el legislador aceptable dentro del sistema constitucional actual. Hasta aquí no hay objeción alguna en lo que respecta al derecho fundamental a la igualdad. El problema se presenta con la ley de 9 de febrero de 1912 al establecer que en caso de que la Cámara deniegue la autorización para proceder judicialmente contra uno de sus miembros se producirá el sobreseimiento libre.

Es aquí donde se produce la quiebra de la igualdad, tanto desde la perspectiva de los derechos fundamentales como desde la perspectiva de los principios constitucionales enunciados en los artículos 1.1 y 9.2 de la Constitución. ¿Por qué tratar a las partes de un procedimiento judicial de forma diferente, perjudicando claramente a una de ellas? ¿ existe alguna razón que justifique esa desigualdad?

\section{d) El test de la razonabilidad de la desigualdad}

Como afirma Martínez Tapia ${ }^{33}$, ha de existir una conexión lógica, directa y efectiva entre los distintos elementos que venimos analizando, es decir, el trato desigual que se impone, el supuesto de hecho que lo justifica y la finalidad que se persigue. Si hay relación de idoneidad — de necesidad o, al menos, de conveniencia - entre esa finalidad y la medida impugnada, ésta será razonable, y la desigualdad estará justificada; pero si el nexo racional quiebra, entonces los criterios diferenciadores resultan inconsistentes con la finalidad. Así lo afirma el Tribunal Constitucional en su Sentencia 114/1987 (Fj. 3. ${ }^{\circ}$ ): "el principio de igualdad impone como canon de constitucionalidad que la exigencia normativa guarde una directa y razonable relación con la finalidad perseguida".

Además no sólo ha de enjuiciarse la finalidad perseguida, sino también los efectos de la medida, ya que el medio que la norma establece para lograr ese

32 MARTÍNEZ TAPIA, RAMÓN: Igualdad y razonabilidad..., op. cit., p. 121.

33 Ibidem, p. 123. 
fin no puede imponer sacrificios desproporcionados o muy gravosos por sus consecuencias.

Con todo lo anterior, si aplicamos el criterio al que habitualmente acude el Tribunal Constitucional en relación con los conflictos en los que están en juego derechos fundamentales, esto, el de la proporcionalidad, constatamos que no existe una relación razonable de proporcionalidad entre los medios empleados y los fines perseguidos. Pues el fin de la inmunidad parlamentaria no se ve en absoluto afectado por el hecho de que se abra un proceso penal contra un ex-parlamentario, y sin embargo se sacrifica sin razón alguna el derecho fundamental a la igualdad de la persona afectada por la conducta presuntamente ilícita de aquel.

Por todo ello consideramos que la previsión del artículo 7 de la Ley de 9 de febrero de 1912 vulnera la igualdad reconocida por la Constitución de 1978, tanto en su vertiente de derecho fundamental como en su expresión de valor y principio constitucional, al prever, de forma injustificada, una consecuencia jurídica que impide que los afectados puedan ver satisfechas sus pretensiones ante los Tribunales de justicia.

ABSTRACT. The aim of this work is to present a concise analysis of the parliamentary immunity prerogative in relation to the right to equality. According to that established in a pre-constitutional Law of 1912, if the Legislative Chamber denies a rogatory letter, the criminal case is definitively rejected and it can not be reopen in the future, when the parliamentarian involved in the case leaves his or her position. We have made an analysis of the equality in the constitutional seat in order to verify if the aforementioned Law of 1912 is or is not contrary to the right to equality which is recognized in the article 14 of the Spanish Constitution. 